SSLA, 24, 249-260

DOI: 10.1017.S0272263102002097

\title{
FREQUENCY EFFECTS AND SECOND LANGUAGE ACQUISITION
}

\section{A Complex Picture?}

Susan M. Gass

Michigan State University

Alison Mackey

Georgetown University

\begin{abstract}
In this response to Ellis's target article on frequency in language processing, language use, and language acquisition, we argue in favor of a role for frequency in several areas of second language acquisition, including interactional input and output and speech processing. We also discuss areas where second language acquisition appears to proceed along its own route and at its own pace regardless of the frequency of the input, as well as areas where input is infrequent but acquisition appears to be unimpeded. Our response is intended to highlight the complexity of the task of deciphering the role and importance of frequency.
\end{abstract}

The field of second language acquisition (SLA) has seen an increased emphasis on psycholinguistic issues in recent years. This can be observed both in the content of articles (e.g., Ellis \& Schmidt, 1998, on connectionism; Schmidt, 2001, on attention) and in the methodologies that have been used of late (e.g., Gass, 2001; Juffs \& Harrington, 1995; Mackey, Philp, Egi, Fujii, \& Tatsumi, in press). Nick Ellis continues this trend, tackling the vexed topic of frequency effects in language processing, language use, and language acquisition.

Address correspondence to: Susan Gass, English Language Center, A-714 Wells Hall, Michigan State University, East Lansing, MI 48824-1027; e-mail: gass@pilot.msu.edu. 
As Ellis points out, the concept of frequency has been discussed by linguists and L2 researchers for quite some time. As long ago as the 19th century, Baudoin de Courtenay (1895) took a position reminiscent of the one taken by Ellis. In talking about alternations in language, he stated that "... every member of a given speech community is bound to acquire by his own mental effort through accumulating and generalizing individual associations" (p. 203). Bloomfield (1933) attributed at least some part of language change to frequency: "Fluctuation in the frequency of speech-forms is a factor in all nonphonetic changes" (p. 392, emphasis in original).

Introductory SLA texts are cautious about the role of frequency. LarsenFreeman and Long (1991) suggested that preliminary data are generally supportive of a role for frequency but that causal claims should not be made. R. Ellis (1994) claimed that:

Overall there is very little evidence to support the claim that input frequency affects L2 acquisition but there is very little evidence to refute it. Perhaps the safest conclusion is that input frequency serves as one of the factors influencing development, often in association with other factors such as L1 transfer and communicative need. (p. 273, emphasis in original)

Gass and Selinker (2001, from Gass, 1988) underscored the complexity of the issue:

\begin{abstract}
Something which is very frequent in the input is likely to be noticed. On the other hand, particularly at more advanced stages of learning, stages at which expectations of language data are well-established, something that is unusual because of its infrequency may stand out for a learner. (p. 402, emphasis in original)
\end{abstract}

Discussions of learners' sensitivity to input features have been a common theme in the field of SLA. Early research by Wagner-Gough and Hatch (1975), Larsen-Freeman (1976), Hamayan and Tucker (1980), and Lightbown (1983) presented findings on input frequency and learning, a general line of inquiry that has continued with interesting results. For example, Bardovi-Harlig (1987) claimed that input frequency can override the assumed difficulty of learning marked features, and Gass and Lakshmanan (1991) found a correlation between (ungrammatical) input and output data. However, until recently, the issue of frequency of patterns in the input has not been systematically investigated. Nick Ellis's target article takes us on a tour of research into frequency effects in language processing and acquisition. He argues that frequency is a fundamental cognitive mechanism in every domain of language processing: phonology, phonotactics, reading, spelling, lexis, morphosyntax, pragmatics, sentence production, and comprehension. Ellis's comprehensive article is a welcome addition to the field of SLA, suggesting ways in which work on frequency may link relatively disparate areas and providing a clearer articulation of the construct. 
We approach our response in two ways. First, in relation to several aspects of the SLA process, we provide further argumentation and possible evidence in favor of Ellis's frequency-based account. Second, we discuss areas of second language learning that we believe are not adequately accounted for on the basis of frequency, or where frequency explanations might be considered a "stretch." We conclude by raising issues that we hope will stimulate additional debate on frequency effects in language processing and language learning. Much of the work that Ellis discusses is based on research in native language acquisition and performance. Our remarks, although addressing some general issues of language, depart from this emphasis and switch the focus to SLA.

\section{ARGUMENTS IN FAVOR OF A FREQUENCY-BASED ACCOUNT}

\section{Input and Interaction}

In Ellis's view, "communicative [teaching] approaches give input, time-on-task, and opportunity for relating form and function. All of this is necessary for developing the associations required for language learning" (p. 175). How these associations are developed clearly requires further specification. We suggest that research examining the role of input and interaction in SLA may benefit from a consideration of the role of input frequency in converting patterns in the input to intake (Gass, 1997).

In his Interaction Hypothesis, Long (1996) proposed that conversational interaction promotes L2 development because interaction "connects input, internal learner capacities, particularly selective attention, and output in productive ways" (pp. 451-452). Much of the current line of interactionist research in SLA addresses the question of how interaction works to bring about L2 development, focusing on issues such as the relative developmental contributions of positive and negative evidence and enhanced salience (Leeman, 2000), together with explorations of the specific nature and contribution of different interactional features to L2 learning.

A consideration of frequency of patterns in the input may be useful for current formulations of questions and explanations about how interaction facilitates L2 learning. As Ellis points out, opportunities for relating form and function are important for developing strong targetlike associations. Interactional modifications during conversation can present ideal opportunities for relating form and function. For example, through interaction, forms in the input are often repeated, rephrased, and segmented (Pica, 1994), thereby providing learners with a greater likelihood of making appropriate form-function connections. Furthermore, interactional modifications may present or provide recasted forms in semantically transparent contexts, which some researchers have argued frees up cognitive resources for attention to be directed toward form (VanPatten, 1996). A frequency-based explanation of SLA may be considered compatible with interactionist claims in that interactional modifications 
might be claimed to impact development through facilitating pattern identification, recognition (of matches and mismatches), and storage. Further specification of this process by researchers working in this area would be helpful in designing research to test such claims.

\section{Output in the Context of Interaction}

Swain $(1995,1998)$ discussed ways in which output may facilitate learning. She argued that attempting to produce the target language may direct learners' attention to relevant input, generating linguistic knowledge that is new, or consolidating the learner's existing knowledge. Swain's claims about output are also compatible with frequency-based accounts of L2 learning. For example, it is possible that output functions as a priming mechanism for future input. As Swain noted, during interaction learners often recognize or notice what Schmidt and Frota (1986) have described as a "gap." One of the functions of interactional input and output may be to provide learners with multiple exemplars of targetlike input (both tokens and types), in a way that allows them, as active participants in interaction, to connect form and meaning at exactly the right time (see Samuda, 2001), providing and strengthening more targetlike schemas at exactly the moment when problems arise. In other words, the process of producing or struggling to produce output may sensitize learners to patterns and associations in future input, possibly making future input more salient. Swain (1995) argued that having consistent opportunities to produce language is crucial for learners and that "their output is the 'selector' for what will be attended to" (p. 131). ${ }^{1}$ The relationship between output frequency on the one hand, and input saliency and frequency on the other, is clearly an important one that requires more research, for both human and machine learning, as discussed in the next section.

\section{Computational Speech Recognition}

As Ellis points out, frequency-based explanations and approaches are gaining recognition in many areas where linguistics is applied. For example, as Jurafsky and Martin's (2000) comprehensive introductory text noted, the earliest systems in the field of speech recognition were symbolic or rule based and were derived primarily from the system developers' intuitions about language. However, in the last 30 years or so, the speech-recognition field has moved to an exclusive focus on frequency-based systems. Based on statistical models of annotated empirical data, these systems have proven to be far more accurate and adaptable than rule-based systems. One of the most popular approaches is based on frequency models of three-word sequences called trigrams (Jelinek, 1976). For example, speech recognizers would be much more likely to accurately perceive the sequence in order to rather than the acoustically similar in over to based primarily on relative frequency.

Computer memory limitations were the primary reason why the speech- 
recognition field was not usually able to utilize longer sequences. Despite these limitations to the dominant frequency-based approaches, the recent trend in speech recognition has not been to abandon frequency methods but rather to augment them with richer linguistically based representational structures capable of generalization and sensitive to long-distance linguistic dependencies. By providing speech-recognition systems with enriched representational frameworks, accuracy can be increased significantly and the number of training sentences needed to achieve comparable system performance is significantly reduced.

In other words, recent work in statistical natural language processing has found that performance can be improved by employing frequency-based learning at multiple levels of context granularity and using representational structures richer than simple surface word sequences. System performance remains highly dependent on the quantity of training input, but by focusing on more salient structures, frequency-based learning by computers has become more accurate and efficient. The link between saliency, frequency, and the perceptions of patterns in the input is clearly also important for human learning of L2s, as discussed previously.

\section{ARGUMENTS AGAINST A FREQUENCY-BASED ACCOUNT}

The preceding sections have described areas where we view the issue of frequency of the input as directly relevant. In the following sections, we discuss areas where acquisition appears to proceed at its own pace regardless of the frequency of the input, as well as areas where input is infrequent but acquisition appears to be unimpeded. The points we make do not rule out a role for frequency-based accounts; rather, they suggest the complexity of the task of deciphering the role and importance of frequency.

\section{Developmental Sequences in L2 Learning}

One area of SLA where a simple frequency explanation seems questionable is the developmental sequences, or pathways, that have been proposed to apply to all learners. For example, in Pienemann and Johnston's (1986) implicational scale of morphosyntax in ESL, ${ }^{2}$ third-person singular $-s$ is a late acquired structure (appearing only at the fifth stage in a six-stage sequence). In their model, until learners have the processing capacity necessary for forms at the preceding stage of acquisition, they do not acquire third-person singular $-s$ regardless of instruction, feedback, or any other intervention, and the many exemplars that appear in the input.

Of course, third-person singular $-s$ is a form with low communicative value. Ellis has argued that "relations that are not salient or essential for understanding the meaning of an utterance are otherwise only picked up very slowly, if at all" (p. 175). However, other forms of higher communicative value in Pienemann and Johnston's (1986) model have also been shown to be acquired in a 
particular developmental order, regardless of input frequency. For example, question formation has been an object of investigation in a number of recent studies in both classroom (Lightbown \& Spada, 1999; Spada \& Lightbown, 1993) and laboratory (Mackey, 1999) contexts. Such studies have generally shown that regardless of the input, higher level question forms are acquired when learners are developmentally ready-that is, when they reach the correct level and have "processing space" for the forms. ${ }^{3}$

However, the existence of developmental sequences does not necessarily rule out a role for frequency. A number of researchers have argued that, when learners are not at the correct developmental level to make immediate use of input, it may be stored and made available at a later time for processing and use (Gass, 1997; Mackey \& Philp, 1998). If frequency is argued to play a role in such a process, further specification of a frequency-based account would be helpful. For example, can patterns be derived from the input, stored in longterm memory, and activated when learners are ready to make (and strengthen) the connections? If so, what governs the activation of these patterns?

\title{
Ungrammaticality
}

Ellis claims that:

\begin{abstract}
The knowledge underlying fluent use of language is not grammar in the sense of abstract rules or structure but a huge collection of memories of previously experienced utterances. These exemplars are linked, with like kinds being related in such a way that they resonate as abstract linguistic categories, schema, and prototypes. Linguistic regularities emerge as central tendencies in the conspiracy of the database of memories of utterances. (pp. 166-167)
\end{abstract}

However, we argue that this view of linguistic knowledge does not capture the totality of linguistic knowledge. Part of what we as humans know about language includes knowledge about grammaticality and ungrammaticality. Ellis deals with the notion of grammatical sentences, arguing that "the acquisition of grammar is the piecemeal learning of many thousands of constructions and the frequency-biased abstraction of regularities within them" (p. 144). If learning is based on frequency in the input, however, how does one learn what is ungrammatical? ${ }^{4}$

SLA research on adverb placement raises interesting questions for frequency-based arguments (Trahey, 1996; Trahey \& White, 1993; White, 1991). The major concern was how learners, in this case French children learning English, know that something is ungrammatical in the L2. French and English have important differences in adverb placement. English allows adverbs between subjects and verbs (SAV; e.g., She always runs fast) but does not allow adverbs to occur between verbs and objects (SVAO; e.g., *She eats always chocolate). French, on the other hand, allows SVAO sentences (e.g., Marie joue quelquefois du piano "Marie plays sometimes the piano") but not SAV sen- 
tences (e.g., *Marie quelquefois joue du piano "Marie sometimes plays the piano"). Thus, French learners of English have to learn that English allows SAV order and that it does not allow SVAO order.

Trahey and White (1993) explored the developmental effects of appearances of the form in the input. Fifth-grade classes of French students studying English received an input flood of English adverbs (positive evidence only) over a 2-week period. Trahey and White found that positive evidence in the input was sufficient for learners to notice that SAV order is possible in English but was insufficient to detect the ungrammaticality of SVAO sentences. Thus, frequency of occurrence in the input provided information about grammaticality but not about ungrammaticality. ${ }^{5}$ Their research showed that positive evidence can reveal to learners the presence of information in the L2 that is different from their native language, but negative evidence may be necessary to show what is not possible in the L2 in those instances in which it is possible in the native language (White, 1991; see also counterarguments by Schwartz \& Gubala-Ryzak, 1992, and White's [1992] response). Thus, it was argued that positive evidence alone, which can be related to frequency of input, appears not to be sufficient to acquire full information about the target language.

Again, such research does not necessarily rule out an explanatory role for frequency of the input. Generative linguists argue that innate constraints explain knowledge about grammaticality and ungrammaticality that cannot be obtained from the input alone and that negative evidence is unreliably provided. Another type of evidence that has been proposed is indirect negative evidence (see Chomsky, 1981, and descriptions by Gass, 1997; Pinker, 1989; Plough, 1995; White, 1989). Arguments for indirect negative evidence suggest that an absence of structures or forms in expected environments can result in forms being excluded from the grammar (Chomsky, 1981, p. 9). Thus, in this view, lack of input (the extreme negative end of frequency) provides crucial information for grammatical construction.

\section{Abstract Syntax}

The UG approach to SLA begins from the perspective of learnability, assuming innateness as a mechanism necessary to account for the complexities of acquisition. This, of course, is in direct opposition to Ellis's view that "all linguistic units are abstracted from language use" (p. 144). As discussed, generative linguists claim that frequency of the input is insufficient for children to attain the complexities of adult grammars. Innate linguistic properties fill in where the input (i.e., frequency effects) fails. Fluent L1 speakers learn properties of grammar that are not learnable from input as illustrated by the use of wanna (from want to) in English discussed by White (1989). To account for those instances in which the sequence want to cannot be replaced by the informal wanna, White proposed that there are principles of UG involving question formation that account for the distribution of these English forms (e.g., * Who do 
you wanna win the race? vs. Who do you want to win the race?). In particular, following movement of the wh-word, a trace is left behind that effectively blocks contraction of want to to wanna. Frequency effects in the absence of some innately specified linguistic properties do not reveal the abstraction necessary to rule out ungrammaticality, as it is not clear how abstractions of this sort can come from language use. Ellis claims that learners are able to abstract linguistic units and patterns through frequent exposure. In other words, no mechanism is presented to show how learners make abstractions of the sort necessary to account for the complexity of language.

\section{Native Language Effects}

Research on the role of the native language in SLA has shown that it can impact learning in both positive and negative ways. It is possible that frequency effects are intertwined with native language effects in relation to some aspects of learning. The fact that frequency effects cannot be considered in isolation is made clear by Ellis himself; he cites perceptual salience, semantic complexity, morphophonological regularity, and other factors that interact with frequency. We add the concept of transfer to this list.

In early work, Zobl (1982) discussed research by Henkes (1974), who presented observational data from three children (French, Arabic, and Spanish speakers) learning English. The analysis was based on the acquisition of the English copula-a form present in French, Spanish, and English but absent in Arabic. Despite similarities in the English input, the three children failed to use the copula in the same way in English. ${ }^{6}$ Although similar patterns of copula use were observed in the initial stages for all three children, the Arabicspeaking child used the copula variably, even at a fairly advanced state of syntactic acquisition, whereas the other two children employed the copula consistently at advanced levels. The explanation provided for the different uses of the copula related to the absence versus presence of the copula in the native languages of the children. Thus, input frequency was insufficient to account for L2 ability without considering the children's L1 background in relation to the target language.

A second example presented by Zobl (1982) relates to paths of acquisition. He compared the acquisition of the English definite article by a Chinese-speaking child and a Spanish-speaking child. In specific reference to articles, Ellis acknowledges the insufficiency of a frequency-based account: "frequency is not a sufficient explanation; otherwise we would never get beyond the definite article in our speech" (p. 178). Although articles are always frequent in the input, other factors intervene. In particular, Zobl argued that in instances where there is zero contrast between the native and target languages (i.e., there is a category in one that does not exist in the other), learners may create "a developmental structure to bridge the gap between zero representation" (p. 174) and the target form. In the case of the Chinese-speaking child, whose native language has no articles, the use of a demonstrative pronoun, 
usually this, provided early evidence of a form that appeared to serve the function of marking definiteness. The use of this marking definiteness developmentally preceded the article the. On the other hand, for the Spanish-speaking child, both this and the were frequently used from the beginning of data collection in accordance with English norms. Again, the developmental differences between the two children suggest that their native languages led them down two different paths-the Chinese-speaking child through a bridge stage in which this occurred before the definite article and the Spanish-speaking child from a starting point in which the definite article and the demonstrative this co-occurred. These case studies suggest that it might be worthwhile to further investigate the interaction between frequency of input and the role of the L1.

\section{CONCLUSION}

Although we have found ourselves generally in agreement with Ellis's characterization of the important role of frequency in SLA, we suggest that a complex task lies ahead. Ellis has presented a convincing picture of the role of frequency in many facets of language. However, an issue of central importance that remains to be addressed relates to exactly how frequency effects interact with other aspects of the SLA process. We are optimistic that Ellis's article will eventually drive more empirical studies of the role of frequency in SLA. We believe that longitudinal studies of the effects of input frequency and L2 learning outcomes, involving learners at different stages of learning and considering the role of the L1, are crucial next steps in the ongoing debate and investigation of frequency effects. Another area worthy of research attention is the relationship between maturational constraints and frequency effects. It is possible that age differences relate to sensitivity to frequency of input and storage, and that this may also help to explain differences between L1 and L2 acquisition. The role of individual differences in SLA, including the importance of working-memory capacity in frequency-based accounts, together with learner strategies, also seems worthy of empirical work. Finally, a better understanding of the role of noticing of the input (in particular, of different levels and types of noticing), and especially in relation to the salience of input, seems crucially important in our ongoing investigations of SLA processes in the context of a frequency-based explanation. It is our hope that this debate will continue.

\section{NOTES}

1. Mackey (2000) reported some empirical support for this claim. She described an episode in which, after trying to figure out the word bumblebee during interaction, a learner's retrospective verbal report can be interpreted as suggesting that she thought she might be more attentive to subsequent input:

I know I hear this word before. In my host family, they er we try er capture many [insek] in bottle. Wasp and hornet and bumblebee. But I have not XX catch this exact pronounce. Now I remember this (laughs). Not [bundul] I see now. Next time our bot- 
tle is empt-er empty, I can know er understand what he say inside [insek]. So, I feel glad about this talk.

2. Although not universally accepted, various empirical studies have provided support for the developmental features of Pienemann and Johnston's (1986) model in an interesting range of experimental and classroom contexts (see Pienemann, 1998).

3. Tarone and Liu (1995) pointed to the need for further studies of putative universal acquisitional orders and referred to frequency in the context of one learner's acquisition of forms supposedly beyond his current level. They explained this phenomenon by discussing "the researcher's intensive use of stage 4 and 5 forms in the input, together with increased opportunity for Bob to produce such forms" (p. 122).

4. Ellis raises the issue of language use and preference in reference to grammatical knowledge. For example, he discusses the syntactic priming effects represented by the work of Bock and her colleagues as tending to "produce the most probable utterance for a given meaning on the basis of the frequencies and recencies of utterance representations" (p. 162). Although this may be representative of what is preferred, it says little or nothing about what is grammatical or what is ungrammatical; it only says that X is preferred. Y may be grammatical or ungrammatical; non-use tells us nothing about its grammatical status. Additionally, of course, immediate use cannot be equated automatically with learning.

5. Trahey (1996) showed that an abundance of positive evidence a year after exposure yielded knowledge of grammatical sentences, but again did not succeed in eradicating the ungrammatical sentences.

6. Zobl (1982) did not specify exact amounts of input, but based on his description, it seems a reasonable assumption that the children were in comparable ESL situations and exposed to generally comparable input. Thus, all things being equal, the frequency effects of input could be expected to be comparable for all three children.

\section{REFERENCES}

Bardovi-Harlig, K. (1987). Markedness and salience in second language acquisition. Language Learning, 37, 385-407.

Baudoin de Courtenay, J. 1895. An attempt at a theory of phonetic alternations. In E. Stankiewicz (Trans.), A Baudoin de Courtenay anthology: The beginnings of structural linguistics (pp. 144-212). Bloomington: Indiana University Press.

Bloomfield, L. (1933). Language. New York: Holt, Rinehart, \& Winston.

Chomsky, N. (1981). Lectures on government and binding. Dordrecht: Foris.

Ellis, N. C., \& Schmidt, R. (1998). Rules or associations in the acquisition of morphology? The frequency by regularity interaction in human and PDP learning of morphosyntax. Language and Cognitive Processes, 13, 307-336.

Ellis, R. (1994). The study of second language acquisition. Oxford: Oxford University Press.

Gass, S. (1988). Integrating research areas: A framework for second language studies. Applied Linguistics, 9, 198-217.

Gass, S. (1997). Input, interaction, and the second language learner. Mahwah, NJ: Erlbaum.

Gass, S. (2001). Sentence matching: A reexamination. Second Language Research, 17, 421-441.

Gass, S., \& Lakshmanan, U. (1991). Accounting for interlanguage subject pronouns. Second Language Research, 7, 181-203.

Gass, S., \& Selinker, L. (2001). Second language acquisition: An introductory course (2nd ed.). Mahwah, NJ: Erlbaum

Hamayan, E., \& Tucker, R. (1980). Language input in the bilingual classroom and its relations to second language achievement. TESOL Quarterly, 14, 453-468.

Henkes, T. (1974). Early stages in the non-native acquisition of English syntax: A study of three children from Zaire, Venezuela, and Saudi Arabia. Unpublished doctoral dissertation, Indiana University, Bloomington.

Jelinek, F. (1976). Continuous speech recognition by statistical methods. IEEE, 64, 532-556.

Juffs, A., \& Harrington, M. (1995). Parsing effects in L2 sentence processing: Subject and object asymmetries in wh-extraction. Studies in Second Language Acquisition, 17, 483-516.

Jurafsky, D., \& Martin, J. H. (2000). Speech and language processing: An introduction to natural language processing, computational linguistics, and speech recognition. Englewood Cliffs, NJ: Prentice-Hall.

Larsen-Freeman, D. \& Long, M. H. (1991). An introduction to second language acquisition research. London: Longman. 
Larsen-Freeman, D. (1976). An explanation for the morpheme acquisition order of second language learners. Language Learning, 26, 125-134.

Leeman, J. (2000, March). Investigating recasts and L2 development: Negative evidence and enhanced salience. Paper presented at the annual meeting of the American Association of Applied Linguistics, Vancouver, Canada.

Lightbown, P. M. (1983). Exploring relationships between developmental and instructional sequences in L2 acquisition. In H. Seliger and M. Long (Eds.), Classroom-oriented research in second language acquisition (pp. 217-243). Rowley, MA: Newbury House.

Lightbown, P. M., \& Spada, N. (1999). Instruction, first language influence, and developmental readiness in second language acquisition. The Modern Language Journal, 83, 1-22.

Long, M. H. (1996). The role of the linguistic environment in second language acquisition. In W. C. Ritchie \& T. K. Bhatia (Eds.), Handbook of second language acquisition (pp. 413-478). San Diego, CA: Academic Press.

Mackey, A. (1999). Input, interaction, and second language development: An empirical study of question formation in ESL. Studies in Second Language Acquisition, 21, 557-587.

Mackey, A. (2000, March). Interactional feedback on L2 morpho-syntax: Learners' perceptions and developmental outcomes. Paper presented at the annual meeting of the American Association of Applied Linguistics, Vancouver, Canada.

Mackey, A., \& Philp, J. (1998). Conversational interaction and second language development: Recasts, responses, and red herrings? The Modern Language Journal, 82, 338-356.

Mackey, A., Philp, J., Egi, T., Fujii, A., \& Tatsumi, T. (in press). Individual differences in working memory, noticing of interactional feedback, and L2 development. In P. Skehan \& Robinson, P. (Eds), Individual differences in L2 learning. Amsterdam: Benjamins.

Pica, T. (1994). Research on negotiation: What does it reveal about second-language learning conditions, processes, and outcomes? Language Learning, 44, 493-527.

Pienemann, M. (1998). Language processing and second language development: Processability theory. Amsterdam: Benjamins.

Pienemann, M., \& Johnston, M. (1986). An acquisition based procedure for second language assessment (ESL). Australian Review of Applied Linguistics, 9, 92-122.

Pinker, S. (1989). Learnability and cognition. Cambridge, MA: MIT Press.

Plough, I. (1995). Indirect negative evidence, inductive inferencing, and second language acquisition. In L. Eubank, L. Selinker, \& W. M. Sharwood Smith (Eds.), The current state of interlanguage: Studies in honor of William E. Rutherford (pp. 89-105). Amsterdam: Benjamins.

Samuda, V. (2001). Guiding relationships between form and meaning during task performance: The role of the teacher. In M. Bygate, P. Skehan, \& M. Swain (Eds.), Researching pedagogic tasks: Second language learning, teaching, and testing (pp. 119-140). London: Longman.

Schmidt, R. (2001). Attention. In P. Robinson (Ed.), Cognition and second language instruction (pp. 3-32). New York: Cambridge University Press.

Schmidt, R., \& Frota, S. (1986). Developing basic conversational ability in a second language: A case study of an adult learner of Portuguese. In R. Day (Ed.), Talking to learn: Conversation in second language acquisition (pp. 237-326). Rowley, MA: Newbury House.

Schwartz, B., \& Gubala-Ryzak, M. (1992). Learnability and grammar reorganization in L2A: Against negative evidence causing the unlearning of verb movement. Second Language Research, 8, 1-38.

Spada, N., \& Lightbown, P. M. (1993). Instruction and the development of questions in L2 classrooms. Studies in Second Language Acquisition, 15, 205-224.

Swain, M. (1995). Three functions of output in second language learning. In G. Cook \& B. Seidlhofer (Eds.), Principle and practice in applied linguistics (pp. 125-144). Oxford: Oxford University Press.

Swain, M. (1998). The Output Hypothesis, focus on form, and second language learning. In V. Berry, B. Adamson, \& W. Littlewood (Eds.), Applying linguistics: Insights into language in education (pp. 1-21). Hong Kong: English Centre, University of Hong Kong.

Tarone, E., \& Liu, G. (1995). Situational context, variation, and second language acquisition theory. In G. Cook \& B. Seidlhofer (Eds.), Principle and practice in applied linguistics (pp. 107-124). Oxford: Oxford University Press.

Trahey, M. (1996). Positive evidence in second language acquisition: Some long-term effects. Second Language Research, 12, 111-139.

Trahey, M., \& White, L. (1993). Positive evidence and preemption in the second language classroom. Studies in Second Language Acquisition, 15, 181-204.

VanPatten, B. (1996). Input processing and grammar instruction in second language acquisition. New York: Ablex 
Wagner-Gough, K., \& Hatch, E. (1975). The importance of input in second language acquisition studies. Language Learning, 25, 297-308.

White, L. (1989). Universal Grammar and second language acquisition. Amsterdam: Benjamins.

White, L. (1991). Adverb placement in second language acquisition: Some effects of positive and negative evidence in the classroom. Second Language Research, 7, 133-161.

White, L. (1992). On triggering data in L2 acquisition: A reply to Schwartz and Gubala-Ryzak. Second Language Research, 8, 120-137.

Zobl, H. (1982). A direction for contrastive analysis: The comparative study of developmental sequences. TESOL Quarterly, 16, 169-183. 